\title{
Immunohistochemical expression of clusterin in colorectal carcinoma
}

\begin{tabular}{ccc}
\hline Jalal Ali J alal $^{1}$ & ${\text { Zheen } \text { Othman }^{1 *}}$ & Payman Anwar $^{1}$ \\
\hline Abstract &
\end{tabular}

Background and objective: Colorectal cancer is a heterogeneous malignancy characterized by a wide range of genetic and epigenetic alterations. Clusterin is a heterodimeric glycoprotein widely expressed in a variety of tissues and secreted in many body fluids. Increased clusterin expression has been reported in the normal colonic mucosa, benign polyps, and colorectal carcinoma. This study aimed to detect the frequency of the clusterin immunoexpression in colorectal carcinoma and determine its association with some clinicopathological parameters.

Methods: Sixty formalin-fixed paraffin-embedded sections of colorectal adenocarcinoma were obtained and randomly selected from the histopathology laboratory at Rizgary Teaching Hospital and some private histopathology laboratories in Erbil city over two years between December 2016 and December 2018. All patients had been diagnosed to have primary colorectal adenocarcinoma and had undergone surgery. The clinicopathological characteristics of the tumors were revised, and the specimens were analyzed immunohistochemically using anticlusterin mouse monoclonal antibody.

Results: Twenty eight cases $(46.6 \%)$ were labeled as clusterin positive, while 32 cases $(53.4 \%)$ were negative for clusterin expression. Clusterin expression was significantly associated with the tumor type (Non-mucinous) $(P=0.01)$ and tumor grade (well to moderately differentiated) $(P=0.03)$. At the same time, no significant association was found between clusterin immunoexpression and other clinicopathological characteristics like age, gender, tumor site, and tumor stage.

Conclusion: Our study indicated that clusterin is overexpressed in some colorectal carcinomas and is significantly associated with histological type and grade. These results suggest that clusterin may play a role in colorectal carcinogenesis. Further studies are required to understand the possible mechanism of clusterin association with carcinogenesis and cancer progression.

Keywords: Colorectal cancer; Clusterin; Immunohistochemistry.

\section{Introduction}

Colorectal cancer is the third most common cancer and the second leading cause of cancer-related mortality worldwide, with an estimated more than one million new colorectal cancer cases each year. ${ }^{1}$ Colorectal cancer is ranked the 7th most common cancer in Iraq while it represents the 4th commonest cancer in the Kurdistan region for both genders. ${ }^{2,3}$ Colorectal cancer is a heterogeneous malignancy characterized by a wide range of genetic and epigenetic alterations. ${ }^{4}$ The majority of colorectal cancer cases are sporadic, while the remaining cases are familial with an inherited genetic predisposition. The carcinogenesis of colorectal cancer is a multistep process that begins with the conversion of the normal colorectal epithelium to adenoma. This is followed by consecutive accumulation of molecular alterations that eventually result in invasive carcinoma. ${ }^{5}$ Recent advances in our knowledge regarding the molecular

${ }^{1}$ Department of Basic Sciences, College of Medicine, Hawler Medical University, Erbil, I raq

* Correspondence: zheenothman@gmail.com 
aspects of colorectal cancer may, therefore, hold a considerable promise for the early detection and future development of new prognostic markers and therapeutic targets for colorectal cancer. ${ }^{6}$ Clusterinis a heterodimeric glycoprotein that is widely expressed in a variety of tissues and is secreted in many body fluids. Its expression has been related to numerous physiological processes that confer distinct properties crucial for carcinogenesis and tumor progression, including cellular response to stress, cell apoptosis, DNA repair, cellular senescence, cell adhesion, tissue remodeling, and immune system modulation. ${ }^{7,8}$ Clusterin exists in two isoforms, secretory clusterin, and nuclear clusterin. The secretory form is cytoprotective, conferring the cell prosurvival properties, while the nuclear clusterin is proapoptotic migrating to the nucleus on cytotoxic stress resulting in cell death. The transition from a normal cell to a neoplastic one begins with the overexpression of secretory clusterin and the loss of nuclear clusterin expression. The ratio of secretory/ nuclear isoform correlates with tumor cell survival and with its metastatic potential. ${ }^{9,10}$ Increased clusterin expression has been reported in the normal colonic mucosa, benign polyps, and colorectal carcinoma. Also, abnormal clusterin expression has been noted in different cancers such as prostatic, breast, ovarian, pancreatic, renal, and hepatocellular carcinomas. ${ }^{11,12}$ This study aimed to detect the frequency of the clusterin immunoexpression in colorectal carcinoma and its association with some clinicopathological parameters like age, gender, tumor site, tumor type, tumor grade, nodal involvement, and tumor stage.

\section{Methods}

After obtaining approval of the study protocol from the research ethics committee at the College of Medicine in Hawler Medical University, this retrospective study was carried out. Sixty formalin-fixed paraffin-embedded sections of colorectal adenocarcinoma were obtained and randomly selected from the histopathology laboratory at Rizgary Teaching Hospital and some private histopathology laboratories in Erbil city during two years between December 2016 and December 2018. All patients who had been diagnosed to have primary colorectal adenocarcinoma and had undergone surgery had been selected. None of them had received chemotherapy or radiotherapy before surgery. All the slides were examined, and the most representative tumor block (no necrosis, no much mesenchymal tissue) was selected for the study. Two sections of 4 micrometers thickness were taken from each paraffin embedded tissue block. The first section was stained with Haematoxylin and Eosin (H\&E) staining for histopathological evaluation. The second section was used for immunohistochemical staining. Tumors were divided according to anatomical location into two categories, namely, right and left colon with the rectum. ${ }^{13}$ The histological type was classified into non-mucinous or mucinous while grading was coded as wellmoderately differentiated and poorly differentiated. ${ }^{14}$ Nodal involvement was labeled as positive or negative for involvement. The staging was performed according to American Joint Committee on Cancer (AJCC) and the Union International Contre Le Cancer (UICC). ${ }^{15}$

\section{Immunohistochemical staining:}

Thin sections (four $\mu \mathrm{m}$ ) were cut, mounted on salinized slides, and dried at $60{ }^{\circ} \mathrm{C}$ for about one hour. After the slides had been deparaffinized and rehydrated at room temperature $\left(20-25{ }^{\circ} \mathrm{C}\right)$, they were placed in a xylene bath and incubated for five minutes. Then, they were put in absolute ethanol for 3 minutes and followed by $95 \%$ ethanol for 3 minutes. At last, the slides were immersed in distilled water for a minimum of 30 seconds. A specific epitope retrieval method was used using $10 \mathrm{mmol} / \mathrm{L}$ citrate buffer with distilled water in 1:10 ratio. For clusterin staining, we use 
davidine-biotin-peroxidase complex procedure in the IHC analysis (DakoCytomation, Copenhagen, Denmark). Then the tissue was stained by RDEFNab 01782 (Anticlusterin mouse monoclonal antibody) at dilution of 1:50. Appropriate positive and negative controls were included in each run of IHC. Negative controls were prepared by replacing the primary antibody with distilled water. Positive control for clusterin included sections of clusterin positive ovarian adenocarcinoma.

\section{Clusterin scoring:}

Both staining intensity and the percentage of positive cells were recorded. The immunohistochemical score was calculated by multiplying the proportion of immunopositive tumor cells and staining intensity score. The intensity of clusterin staining was coded as 0 (negative), 1 (weak), 2 (moderate), and 3 (strong). The proportion of immunopositive tumor cells was calculated as $0(0 \%), 1(1-25 \%)$, $2(25-50 \%), 3(50-75 \%)$, and $4(>75 \%)$, indicating the percentage of positive staining tumor cells. A staining index (values 0-12) was obtained, and only samples with a final immuoexpression score of 6 were defined as 'overexpression. ${ }^{12,16,17}$

\section{Statistical analysis:}

The collected data were analyzed using the computerized software statistical package for the social sciences program (version 23). Using the Pearson Chisquare test, the association between clusterin expression and clinicopathological parameters was assessed. The significance level was set at $(P \leq 0.05)$. All patients diagnosed with primary colorectal adenocarcinoma and who had undergone surgery had been selected; none of them had received chemotherapy or radiotherapy before surgery.

\section{Results}

In this study, 60 cases of colorectal cancer have been included. The patient's age ranged from 19-85 years with a mean age of 52.59 years \pm 15.670 years, and the median age was 52 years. There were 24 males and 36 females with a female to male ratio of $1.5: 1$. The clinicopathological characteristics are summarized in Table 1.

Table 1: Numbers and percentages of different clinicopathological characteristics of the studied cases.

\begin{tabular}{llc}
\hline Variables & Categories & No. (\%) \\
\hline Age & $<50$ years & $37(61.7)$ \\
Gender & $\geq 50$ years & $23(38.3)$ \\
& Male & $24(40)$ \\
Tumor site & Female & $36(60)$ \\
& Right & $15(25)$ \\
Tumor type & Left & $45(75)$ \\
& Non-mucinous & $53(88.3)$ \\
Tumor grade & Mucinous & $7(11.7)$ \\
& Well - moderate & $50(83.3)$ \\
Nodal status & Poor & $10(16.7)$ \\
& Positive & $35(58.3)$ \\
Tumor stage & Negative & $25(41.7)$ \\
& I - II & $25(41.7)$ \\
Total & III - IV & $35(58.3)$ \\
\hline
\end{tabular}


Twenty eight cases $(46.7 \%)$ were labeled as clusterin positive, while 32 cases $(53.3 \%)$ were negative, as shown in Figure 1. Clusterin expression was significantly associated with the tumor type being more expressed in non-mucinous type $(P=0.013)$ and tumor grade with more expression in well and moderately differentiated tumors $(P=0.033)$. Although clusterin expression was higher when the lymph nodes were positive and with higher stages, the association was not significant. No significant association was found between clusterin expression and other clinicopathological characteristics like age, gender, and tumor site, as shown in Table 2.

Table 2: Association of clusterin immunoexpression with clinicopathological characteristics.

\begin{tabular}{|c|c|c|c|c|c|}
\hline \multicolumn{2}{|c|}{$\begin{array}{l}\text { Clinicopathological } \\
\text { characteristic }\end{array}$} & \multirow{2}{*}{$\begin{array}{c}\text { Total No. } \\
37\end{array}$} & \multirow{2}{*}{$\begin{array}{c}\text { Clusterin positive } \\
\text { (\%) }\end{array}$} & \multirow{2}{*}{$\begin{array}{c}\begin{array}{c}\text { Clusterin negative } \\
(\%)\end{array} \\
18(48.6)\end{array}$} & \multirow{2}{*}{$P$ value } \\
\hline Age & $<50$ years & & & & \\
\hline & $\geq 50$ years & 23 & $10(43.5)$ & $13(56.5)$ & $0.793^{*}$ \\
\hline \multirow[t]{2}{*}{ Gender } & Male & 24 & $12(50)$ & $12(50)$ & \multirow{2}{*}{$0.793^{*}$} \\
\hline & Female & 36 & $16(44.4)$ & $20(55.6)$ & \\
\hline \multirow[t]{2}{*}{ Tumor site } & Right colon & 15 & $6(40)$ & $9(60)$ & \multirow{2}{*}{$0.756^{*}$} \\
\hline & Left colon & 45 & $22(48.9)$ & $23(51.1)$ & \\
\hline \multirow[t]{2}{*}{ Tumor type } & Non-mucinous & 53 & $27(51)$ & $26(49)$ & \multirow{2}{*}{$0.013^{*}$} \\
\hline & Mucinous & 7 & $0(0)$ & $7(100)$ & \\
\hline \multirow[t]{2}{*}{ Tumor grade } & Well-moderately & 50 & $25(50)$ & $25(50)$ & \multirow{2}{*}{$0.033^{*}$} \\
\hline & $\begin{array}{l}\text { Poorly } \\
\text { differentiated }\end{array}$ & 10 & $1(10)$ & $9(90)$ & \\
\hline \multirow[t]{2}{*}{ Nodal status } & Positive & 35 & $18(51.4)$ & $17(48.6)$ & \multirow{2}{*}{$0.439^{*}$} \\
\hline & Negative & 25 & $10(40)$ & $15(60)$ & \\
\hline \multirow[t]{2}{*}{ Tumor stage } & Stage I and II & 25 & $10(40)$ & $15(60)$ & \multirow[t]{2}{*}{$0.439^{*}$} \\
\hline & Stage III and IV & 35 & $18(51.4)$ & $17(48.6)$ & \\
\hline
\end{tabular}

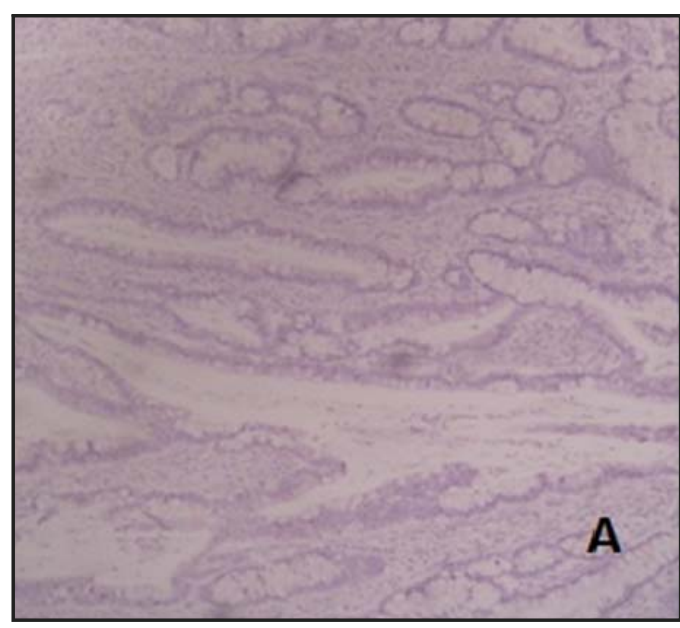

Figure 1: Clusterin immunoexpression. A. Negative clusterin immunoexpression (IHCx100). B. Postive clusterin immunoexpression (IHCx100). 


\section{Discussion}

Most colorectal cancer patients present with advanced stage disease at the time of diagnosis. However, the prognosis and the response to treatment are not the same among patients with the same stage. ${ }^{18}$ New molecular markers are needed for early detection and diagnosis of colorectal cancer to improve therapeutic outcomes and predict prognosis. Clusterin has been regarded as a promising diagnostic and possibly a prognostic indicator of human colorectal cancer. ${ }^{19}$ In the present study, $46.7 \%$ were labeled as positive for clusterin immunoexpression, while $53.3 \%$ were labeled as negative for clusterin immunoexpression. Our results were comparable to results from other studies. ${ }^{12,20,21}$ In this study, the mean age of the patients was $52.59 \pm 15.670$ years. The highest frequency of cases was observed within patients $\geq 50$ years $(61.7 \%$ of patients were 50 years or above). Our results were similar to those obtained by Ali et al. from Iraq. ${ }^{22-24}$ There was no significant association between clusterin immunoexperssion and age of the patient, which was similar to other studies. ${ }^{12,20,21}$ There were 24 males, and 36 females with a female to male ratio of $1.5: 1$ with a slight female predominance which was similar to that obtained by Mahmood and Alrubaie from Iraq. ${ }^{23,24}$ This slight female predominance was unlike other previous studies. ${ }^{17,22,25}$ This may be attributed to age related difference in sex predominance as the male predominance may be age dependent as most of our patients were above $50(61.7 \%)$. It might also be due to genetic and environmental factors or could be just by chance. ${ }^{26}$ There was no significant correlation between gender and clusterin immunoexpression, which was similar to what had been observed by others. $^{12,17,20,21,25}$ Forty five $(75 \%)$ cases had primary tumor of the left colon and rectum, while $15(25 \%)$ cases had tumor in the right colon, which is compatible to the results obtained by other studies, ${ }^{17,21-24}$ with no statistically significant association between clusterin immunoexpression and tumor location as in other studies. ${ }^{12,16,17,21,25}$ Fifty three cases were non-mucinous adenocarcinoma (88.3\%) while only $7(11.7 \%)$ cases being diagnosed with mucinous adenocarcinoma, and the majority being well- moderately differentiated carcinoma (83.3\%), while only $16.7 \%$ had poorly differentiated tumor, this was in concordance with other studies. ${ }^{17,20,21,27,28}$ There was a significant association between clusterin immmunoexpression and the histological type and the grade of colorectal cancer. None of the other similar studies correlated clusterin expression with histological type; however, this significant association in our study may be attributed to that most of our cases were of non-mucinous type, which was mostly well-moderately differentiated, and we stated that there was a significant correlation between histological grade and clusterin being mainly in well-moderately differentiated tumors. Gikas in his published article, showed a similar significant association between clusterin immunoexpression and gradeof the tumor. Similarly, the studies conducted by Kevans and Goma showed a higher expression of clusterin with wellmoderately differentiated tumors without a statistical significance. ${ }^{16,17,21}$ The current study indicated that the clusterin immunoexpression in the patients who had presented with lymph node metastasis were slightly more than those who did not present with lymph node metastasis with no statistically significant association with clusterin immunoexpression, our results were in alignment with the work done by Goma that showed no significant association. ${ }^{21}$ Concerning the association of clusterin immunoexpression with the stage of the disease, it was slightly more expressed in stages III and IV of the disease than stages I and II. However, this association was statistically not significant. This result was in agreement with other studies that claimed that the immunoclusterin immunoexpression was 
associated with more advanced stages, indicating that clusterin is involved in colorectal cancer progression as several other types of carcinoma, including breast, prostate, kidney, pancreatic and ovarian cancers. ${ }^{12,16,25,29,30}$ The possible discrepancy in associations among different studies may be due to differences in the sample size, the methods of antigen retrieval, the type of antibody used, or the methods of clusterin immunohistochemical scoring. This in addition to discrepancies among the pathologists in the evaluation of clusterin immunoexpression scoring.

\section{Conclusion}

Our study indicated that clusterin is expressed in colorectal carcinoma and is significantly associated with histological type and grade. These results suggest that this marker may play a role in colorectal carcinogenesis. Further studies are required to understand the possible mechanism of clusterin association with carcinogenesis and cancer progression.

\section{Competing interests}

The authors declare no competing interests.

\section{References}

1. Bray F, Ferlay J, Soerjomataram I, Siegel RL, Torre LA, Jemal A. Global Cancer Statistics 2018: GLOBOCAN Estimates of Incidence and Mortality Worldwide for 36 Cancers in 185 Countries. Cancer J Clin2018; 68 (6):394-424.

2. Results of Iraqi Cancer Registry (1999-2004), Ministry of health, Iraq Cancer Registry Centre, Baghdad - Iraq; 2008.

3. Othman RT, Abdulljabar R, Saeed A, Kittani SS, Sulaiman HM, Mohammed SA, et al. Cancer incidence rates in the Kurdistan region/Iraq from 2007-2009. Asian Pac J Cancer Prev 2011; 12(5):1261-4.

4. Dan Li. Recent advances in colorectal cancer screening. Chronic Dis Transl Med 2018; 4(3):139-47.

5. Nguyen HT, Duong HQ. The molecular characteristics of colorectal cancer: Implications for diagnosis and therapy. Oncol Lett 2018; 16(1):9-18.

6. Inamura K. Colorectal Cancers: An Update on Their Molecular Pathology. Cancers (Basel) 2018; 10(1):26.
7. Zhang J, Miao C, Xu A, Zhao K, Qin Z, Li X, et al. Prognostic roleof secretory clusterin in multiple human malignant neoplasms: A meta analysis of 26 immunohistochemistry studies. PLoS One 2016; 11(8):e0161150.

8. Andersen $\mathrm{CL}$, Schepeler $\mathrm{T}$, Thorsen $\mathrm{K}$, Demtroder KB, Mansilla F, Aaltonen LA, et al. Clusterin expression in normal mucosa and colorectal cancer. Mol Cell Proteomics 2007; 6(6):1039-48.

9. Trougakos IP, Djeu JY, Gonos ES, Boothman DA. Advances and challenges in basic and translational research on clusterin. Cancer Res 2009; 69(2):403-6.

10. Pucci S, Bonanno E, Sesti F, Mazzarelli $P$, Mauriello A, Ricci $F$, et al.Clusterin in stool: A new biomarker for colon cancer screening. Am J Gastroenterol 2009; 104(11):2807-15.

11. Koltai T. Clusterin: a key player in cancer chemoresistance and its inhibition. Onco Targets Ther 2014; (7):447-56.

12. Xie D, Sham JST, Zeng WF, Che LH, Zhang M, $\mathrm{Wu} \mathrm{HX}$, et al. Oncogenic role of clusterin overexpression in multistage colorectal tumorigenesis and progression. World $\mathrm{J}$ Gastroenterol 2005; 11(21):3285-9.

13. Lore JM, Pereira AAL, Lam M, Willauer AN, Raghav K, Dasari A, et al. Classifying colorectal cancer by tumor location rather than sidedness highlights a continuum in mutation profiles and consensus molecular subtypes. Clin Cancer Res 2017; 24(5):1062-72.

14. Bosman F.T, Carneiro F, Hruban R.H, Theise N.D. Tumors of the colon and rectum. World Health Organization Classification of Tumors. Pathology and Genetics of Tumors of the Digestive System. $4^{\text {th }}$ ed. Lyon, France: IARC Press; 2010. P. 131-83.

15. Amin MB, Edge S, Greene F, Byrd DR, Brookland RK, Washington MK, et al. Colon and Rectum. In: Jessup JM, Richard MG, Elliot AA, AB Benson III, James DB, George JC, eds. AJCC Cancer Staging Manual. 8th ed. Chicago: Springer Nuture; 2017. P. 251-74.

16. Gikas PD, Komborozos VA, Petraki CD, Morris T, Gikas DP. Utility of clusterin as a biomarker in human colorectal neoplasia. Hellenic J Surg 2012; 84(3):150-9.

17. Kevans D, Foley J, Tenniswood M, Sheahan K, Hyland J, Donoghue DO, et al. High clusterin expression correlates with a poor outcome in stage II colorectal cancers. Cancer Epidemiol Biomarkers Prev 2009; 18(2):393-9.

18. Divitiis C, Nasti G, Montano M, Fisichella R, laffaioli RV, Berretta M. Prognostic and predictive response factors in colorectal cancer patients. World J Gastroenterol 2014; 20(41):15049-59.

19. Rodrı AM, Cadena MP, Saco AP, Berrocal FJ. Differential expression of serum clusterin isoforms in colorectal cancer. Mol Cell Proteomics 2006; 5(9):1647-57. 
20. Redondo M, Rodrigo I, Alcaide J, Tellez T, Roldan MJ, Funez R, et al. Clusterin expression is associated with decreased disease-free survival of patients with colorectal carcinomas. Histopathology 2010; 56(7):932-6.

21. Gomaa W, Al-ahwal $M$, Al-maghrabi $H$, Buhmeida A, Al-qahtani, Al-maghrabi BM, et al. Expression of clusterin in colorectal carcinoma in relation to clinicopathological criteria. Malaysian J Pathol 2017; 39(3):243-50.

22. Ali AJ, Al-Ogaili AA, Salih HI. Comparison of colorectal cancer in patients below and above 40 years. Iraqi J Comm Med 2017; 30:1:38-43.

23. Mahmood KI, Namiq KF, Muhamad CA, Muhamad BO, Majed KM, Fattah HN. A descriptive study of colorectal cancer in Hiwa cancer hospital, Sulaymaniyah, Iraq. Science Journal of University of Zakho 2017; 5(3):244-8.

24. AlrubaieA, Alkhalidi N, Abdl-husain S. A clinical study of newly-diagnosed colorectal cancer over 2 years in a gastroenterology center in Iraq. Journal of Coloroctology 2019; 39:(3):217-22.

25.Artemaki PI, Sklirou AD, Kontos CK, Liosi AA, Gianniou DD, Papadopoulos IN, et al. High clusterin (CLU) mRNA expression levels in tumors of colorectal cancer patients predict a poor prognostic outcome. Clin Biochem 2019; 75(2020):62-9.

26. Purim O, Gordon N, Brenner B. Cancer of the colon and rectum: Potential effects of sex-age interactions on incidence and outcome. Med Sci Monit 2013; 19:203-9.

27. Hugen NC, Velde JH, Wilt HW, Nagtegaal D. Metastatic pattern in colorectal cancer is strongly influenced by histological subtype. Ann Oncol 2014; 25:651-7.

28. Razenberg LGEM, Gestel YRBM, Lemmens VEPP, de Wilt JHWD, Creemers GJ, de Hing IHJT. The prognostic relevance of histological subtype in patients with peritoneal metastases from colorectal cancer: a nationwide populationbased study. Clin Colorectal Cancer 2015; 14(4):13-9.

29. Jin J, Kim JM, Hur YS, Cho WP, Lee KY, Ahn SI, et al. Clinical significance of clusterin immunoexpression in pancreatic adenocarcinoma. World J Surg Oncol 2012; 10:146.

30. Yang GF, Li XM, Xie D. Overexpression of clusterin in ovarian cancer is correlated with impaired survival. Int J Gynecol Cancer 2009; 19(8):1342-6. 